\title{
Alternativas a la crisis de la institución escolar desde la pedagogía crítica
}

\section{Elisa Bani Calderón Gill}

Escuela Normal Superior de Michoacán

Rosalía López Paniagua

Centro de Investigaciones Interdisciplinarias en

Ciencias y Humanidades de la UNAM

\section{Resumen}

1 presente ensayo aborda la crisis de $\checkmark$ la institución escolar desde la perspectiva de la Pedagogía Crítica. Busca la reflexión y el análisis de los actores involucrados en los procesos de enseñanzaaprendizaje, así como las posibles alternativas, por lo que se retoman los planteamientos de Adorno, Freire, Illich, Foucault y Giroux como referentes teóricos para impulsar la propuesta de una educación activa, dialógica, que promueva una democracia, entendida no desde las mayorías o las minorías, sino escuchando e incluyendo todas las opiniones. Se propone la participación del docente y del alumno en la conformación del currículo y el desarrollo del mismo en el aula y fuera de ella, adaptando la intelectualidad y el diálogo como pedagogía permanente en las escuelas, que si bien han sido usadas como brazos de control social del sistema hegemónico, hoy es necesario que impulsen la toma de conciencia y la socialización de ideas transformativas que contribuyan a la construcción de una mejor sociedad.

Palabras clave: pedagogía crítica, instituciones escolares, intelectualidad, participación, conciencia. 


\section{Introducción}

El contexto mexicano últimamente ha estado marcado por graves problemas económicos, políticos y sociales, entre los que destaca la crisis de la institución escolar, la cual se ha pretendido superar mediante la puesta en práctica de nueva política educativa impulsada en el marco de una reforma constitucional concretada en el año 2012, cuyo objetivo principal, aunque no se expresa abiertamente, es lograr que la escuela responda, por una parte, a las exigencias de la economía capitalista global, y por otra, a lograr la sumisión y docilidad de las mayorías que requiere su hegemonía.

Es preciso tener en cuenta que se trata de la institución escolar surgida en la modernidad consolidada en el siglo XX, hoy en crisis, porque actualmente la escuela no educa para la vida o, dicho de otro modo, está "desconectada" de la vida y del espacio social de los educandos y educadores, pero sí se ve obligada a responder a las exigencias de la globalización. Sin embargo, la escuela debe concebirse como un espacio socializador, no descartable para la construcción de nuevas formas de ser y resistir, de comprender y actuar sobre sí misma y sobre el mundo, puede potenciar ambientes liberadores que contrarresten su fuerte inclinación opresora debido a su origen moderno-capitalista.

Si bien es cierto que la institución escolar ha sido objeto de transformaciones que van desde la estructura externa a los procesos de su conformación interna (reformas curriculares, formas de evaluación, programas de mejoramiento para el funcionamiento de los planteles escolares, ade- más de la incorporación de los enfoques de inclusión y multiculturalidad), los cambios promovidos distan mucho de dar solución a una crisis que marca, cada vez más, la diferencia entre opresores y oprimidos, entre individuos libres y sometidos de un sistema devorador de conciencias y fracturador de sociedades.

Ante tal situación, es urgente la participación colectiva, activa y responsable de cada individuo para la conformación de una nación libre de pensamiento y expresión, democrática, justa, tolerante, incluyente y abierta, para lo cual la escuela se avizora como el espacio más importante en la formación de individuos críticos, analíticos, reflexivos de su presente y partícipes en la construcción de un mejor futuro común.

En este contexto, el objetivo de este ensayo es reflexionar sobre la crisis que atraviesa actualmente la escuela mexicana y explorar alternativas desde la Pedagogía crítica. Para cumplir con el objetivo propuesto se presentan dos apartados, en el primero se abordan algunos de los factores claves que explican la crisis educativa en México. En el segundo, se proponen posibles alternativas desde la Pedagogía crítica tomando como referencia central el pensamiento de Freire, así como de Adorno y Giroux, para fundamentar una reorientación de la institución escolar en México, que tanto apremia.

Finalmente, en las conclusiones se enfatizan algunos elementos que se consideran centrales, no con el afán de cerrar un círculo, sino de abrir una puerta a la discusión, al diálogo franco y abierto de ideas para construir alternativas a la crisis de la institución escolar. 


\section{En torno a la crisis educativa}

México forma parte de organizaciones mundiales como son la Organización para la Cooperación y Desarrollo Económico (OCDE, 2012), la Organización de Naciones Unidas para la Educación la Ciencia y la Cultura (unEsCo)y la Organización de Estados Iberoamericanos para la Educación, la Ciencia y la Cultura (oEI, 2011) las cuales coinciden en señalar que la educación permite alcanzar una serie de satisfactores y mejorar la calidad de vida de las personas que se benefician con ella.

Sin embargo, en el país se vive un rezago educativo lacerante que se manifiesta en analfabetismo, analfabetismo funcional y exclusión escolar, por mencionar los indicadores más relevantes. El problema es que no se han alcanzado los estándares educativos mínimamente deseables, mucho menos de formación integral de quienes acceden a la educación. Así, desafortunadamente educar (se) para la vida se ha convertido en una meta, cada vez más inalcanzable.

Recientemente en el país, las autoridades gubernamentales han estado esencialmente preocupadas por cumplir las expectativas de las organizaciones internacionales que regulan y evalúan los procesos educativos, señaladamente la OCDE, mediante su Programme for International Students Assesment (PISA) y otras pruebas medianamente adaptadas. Pero, esta meta pudiera no constituir el principal problema, dado que los estándares y los criterios de evaluación no parecen ser los adecuados para las condiciones del país, considerando las dificultades existentes, pobreza, desempleo, inseguridad, etc., las cuales incluso podrían justificar los bajos niveles de aprovechamiento. Lo que realmente preocupa es el alto nivel de insatisfacción en la calidad de vida de las personas.

Si bien es cierto la escuela aún sostiene como objetivo formal, forjar hombres y mujeres con capacidades suficientes para su desarrollo integral en la sociedad, en los hechos se encuentra, cada vez más, orillada a formar esencialmente mano de obra calificada de mediano nivel. Las encuestas realizadas a egresados de las instituciones de educación media y superior, señalan que una vez terminados sus estudios no encuentran trabajo y desarrollan actividades escasamente satisfactorias, ya que poco o nada tienen que ver con sus perfiles profesionales, además de que el salario que reciben es bajo y no alcanza a cubrir sus necesidades básicas (De Vries et al, 2013).

Esta situación hace referencia a la crisis de la institución educativa, desde el nivel básico hasta el superior, la cual reclama una nueva arquitectura, capacitación constante al personal docente y salarios justos, así como instalaciones y ambientes adecuados para el desarrollo del proceso enseñanzaaprendizaje. Además de programas académicos menos densos que permitan la profundización de temáticas necesarias para la vida, así mismo alumnos alimentados y estimulados en sus hogares, con familias que los hagan sentir queridos y participen de su educación. En fin la lista es larga y, cada vez más compleja.

Adicionalmente, destaca el tema de la comunicación entre los educandos y los educadores sobre la cual recientes estudios señalan que las instrucciones dadas por 
los profesores no son atendidas apropiadamente por sus alumnos debido a la falta de una correcta decodificación en el lenguaje, es decir, los alumnos no entienden lo que el docente habla en el salón de clase, ya que ni siquiera reconocen su idioma, lo cual implica lógicamente una ausencia de comunicación por un mensaje decodificado inadecuadamente (Granja, 2007 y 2011).

En cuanto a las formas y/o estilos de enseñanza, cabe señalar — con base en observaciones propias y de otros profesores de los diferentes niveles de educación-, que son diversas; y aunque aseguramos practicar pedagogías participativas y colaborativas, lo cierto es que la percepción que nuestros alumnos tienen de ellas no siempre es acorde con lo que esperamos como maestros, lo cual indica la falta de reflexión, diagnóstico y sistematización de éstas para estructurar nuestras clases, así como evaluaciones acordes, en tiempo y forma, con los estilos de aprendizaje de nuestros alumnos, de manera tal que los estudiantes desarrollen aprendizajes autorregulados buscando los elementos necesarios para su formación, sin necesidad de la marcada limitación del maestro, sino más como una participación orientadora.

Los planes y programas que deberían ser coherentes con las necesidades e intereses de nuestros alumnos, así como la elección de tema y la profundización de los mismos, parecen estar más bien sujetos a la preferencia del profesor, y a veces ni siquiera de él, sino de un sistema educativo abstracto pero omnipresente, que opera con fines mercantiles e ideologizantes, y que suele despojar, tanto al educando como al educador, de su derecho a elegir y participar en la revisión constante y reestructuración de contenidos y la forma de abordarlos.

En México, con la Reforma Educativa del 2012, en el nivel básico se pretende impulsar procesos de enseñanza-aprendizaje de "calidad", entendida ésta como aquella que responde al modelo económico neoliberal, sin tomar en cuenta los procesos sociales no ajenos a la escuela, como el empleo, la pobreza, la violencia, etc. Esta perspectiva descontextualiza, deshumaniza a los alumnos y profesores inmersos en dichos procesos, y aun así se pretende "evaluar la calidad" de la educación, pero lo único que consigue es profundizar la diferencia entre sujetos competentes y no competentes, afectando a alumnos y docentes, además de fracturar aún más el tejido social.

Con este enfoque de la educación lo que efectivamente se busca es el sometimiento de los individuos, incluso voluntariamente, ya que desafortunadamente la creencia en el castigo o premio en las escuelas es un factor que coadyuva al autocontrol. "La disciplina autoritaria, la participación dirigida, la motivación intencionada, la evaluación premeditada, y hasta la asistencia obligada a la escuela, son modos de castigo que alimentan la sumisión, doblegan la voluntad y encierran el cuerpo" (Foucault, 1976:18). Sin duda, no hay peor tortura que vivir bajo los deseos de cualquier interés ajeno al propio, tratar de cumplir con las expectativas de otros, a las que de manera individual cada persona ha de soñar con alcanzar o representar en la vida.

Nada es más terrible que escuchar a los padres de familia amenazar a sus hijos con 
frases tales como: "Ya verás, en la escuela sí te van a educar", "Ahí te harán ver tu suerte". Resulta alarmante concebir a la familia y la comunidad vinculada a esta forma de "educación" amenazante y autoritaria que en nada contribuye a la formación de individuos y ciudadanos libres.

Entonces, a pesar de que se habla de la crisis de la educación, hasta el momento la escuela ha cumplido su función de poder, que aunque invisible, se hace notar en la obligatoriedad, en la conformación del edificio escolar, aislado del exterior, enrejado, cerrado, y en el interior una serie de salones en donde debe imperar el silencio y en el que los educandos, permanecen sentados por horas, como autómatas, y sujetos a procesos ajenos a su conciencia y deseos, reprimidos de cualquier anhelo de cambio y formas de expresión de su interior, en donde se conoce al verdadero yo y lo que le estimula (Foulcault, 1976). Procesos vigilantes de la conformación de personalidades que buscan la representación de un mundo adulto ajeno, lleno de reglas morales, que muchas veces son solo aparentes (doble moral), que no permiten ser cuestionadas y mucho menos desacatadas, ya que de lo contrario no se llegará a ser parte de una sociedad que ha asumido una estructura de poder.

Ante tal situación las interrogantes que surgen son: ¿Acaso la única alternativa es desaparecer las escuelas?, ¿será necesarioadoptar el des-aprendizaje para liberar la capacidad innata de aprender de nuestros alumnos? Un mundo sin escuelas no es para Illich (1979) una propuesta del todo descabellada al contemplar la crisis de la escuela sobre la cual tácitamente señala que la solu- ción no está en las actitudes de los educadores, las cuales se han convertido por años en temas de estudio, tales como, el docente como factor de cambio, innovación y mejora en el proceso de enseñanza-aprendizaje, las metodologías de enseñanza aprendizaje, etc., como insisten las reformas promovidas por la OCDE.

A lo que realmente apuesta y profundiza Illich (1979) es al sentido de generar procesos educativos que aumenten la oportunidad para que cada cual transforme su vida en el momento del aprendizaje, de compartir, de interesarse, es decir, que cada uno sea responsable de nutrir sus procesos formativos, alimentado por el simple, y a la vez complejo, deseo.

La verdadera participación de los actores directamente involucrados en la educación ha de generar sujetos capaces de potencializar la tarea sin coerción, ya que el hambre y deseo de alcanzar metas propias, deseos genuinos, detonarán en un espacio de participación activa sin el látigo del castigo. En donde al aprender se busquen las fuentes originales, en donde el educando sea el que incansablemente construya su búsqueda del conocimiento, sin establecer reglas que obliguen a situarse en un lugar físico determinado, a permanecer un número de horas, sólo para cumplir con estándares sin tomar en cuenta la "calidad" misma del proceso; entendida ésta como el disfrute del diálogo, la interacción y la confrontación con el conocimiento, en compañía de personas que comparten el mismo interés.

Siguiendo a Illich, tal vez, habrá que regresar a la escuela primitiva, pre-moderna, en donde no era necesario un salón de cla- 
ses y un horario, mucho menos uniformes $\mathrm{y}$ útiles escolares que hoy doblegan las espaldas de los educandos con mochilas repletas, y exigentes cuotas escolares que privan a muchas familias de bienes esenciales, ya que sólo cuentan con ingresos mínimos.

Y no es que las herramientas de las que se ha hecho la escuela moderna sean perversas, sino que han perdido el objetivo central de lo que es la escuela y lo necesario para poder echar a andar la imaginación, la creatividad, el interés y la motivación de los alumnos por aprender, por conocer y comprender el mundo visible, aún aquel que escapa a la percepción de nuestros sentidos, alimentar la curiosidad de niños y jóvenes que conozcan un estilo de vida indagatorio, formulando preguntas y encontrando respuestas y/o proponiendo posibles alternativas de solución a los problemas de los que hemos hecho una bola de nieve.

Sin embargo, al destruir el brazo intelectual del sistema en el que se ha convertido la escuela hemos de dar un golpe de timón, quizá muchos convencidos se queden en el camino, aceptando egoístamente los pocos beneficios personales que satisfagan necesidades inmediatas e individuales, dejando de pensar en el colectivo, en lo que somos como sociedad, en lo que implica debilitar al grueso de la población y buscar la individualidad de la que se ha fortalecido el sistema capitalista, hasta el punto del individualismo posesivo (Macpherson, 2005).

Defender la satisfacción personal sin importar el bien común ha sido bandera para el consumismo y el aislamiento de los individuos, cada vez más marcado, como son las escuelas, tanto públicas como privadas, que personalizan la educación para formar individuos capaces y competitivos, sólo centradas en favorecer la meta de mayor beneficio personal.

Esta tendencia individualista, exacerbada y ofensiva, hace necesario iniciar una dinámica de cambio y construcción participativa, en donde cada uno sea consciente de la importancia de su contribución a los procesos de cambio y asuma que se trata de un problema multicausal y social, de todo un país, y así darse cuenta de que la crisis de la institución escolar es reflejo de sí misma.

Los fenómenos de la vida social, incluida la educación, han generado una amplia discusión ontológica, epistemológica, teórica y metodológica, gracias a la cual hoy sabemos que no podemos buscar soluciones unidisciplinarias y unicausales a los problemas emergentes en el campo de la educación. En todas las áreas del conocimiento se hace cada vez más evidente, que la mayoría de los problemas no pueden resolverse disciplinariamente, que su naturaleza es compleja y comprende variadas interacciones.

$\mathrm{Al}$ respecto, al menos durante los últimos 20 años, incluso la UNESCO viene insistiendo en una serie de ideas de máxima relevancia, tales como: La lógica clásica y el pensamiento único generan pobreza; No podemos seguir parcelando el saber; Necesitamos un enfoque transdisciplinario; Es urgente una visión trans-nacional, transcultural, trans-política y trans-religiosa; Debemos adoptar un paradigma sistémico para comprender la complejidad; Es necesario rehacer los planes de estudio; El diálogo como método es imprescindible (CIRETUNESCO, 1997). 
Sin embargo, la tarea a realizar no es fácil, ya que si hay algo verdaderamente difícil, es la toma de conciencia crítica de nuestros propios presupuestos, de nuestro punto de vista, pues frecuentemente están arraigados más afectivamente que racionalmente, incluso a manera de acto de fe.

Por esto, el mismo Kant (1973) muy consciente de ello, recomendaba a sus alumnos que miraran no tanto lo que la gente decía que veía, sino que miraran y examinaran el ojo de esas personas, para así evitar el reduccionismo que impide observar más allá de lo aparente, de lo meramente observable.

Si nos auto-observamos y observamos el ámbito escolar podremos ver que las circunstancias que nos toca vivir nos exigen transitar hacia una manera nueva de conocer, de aprender, de transmitir y recibir conocimiento, de relacionarnos con otros seres humanos, con nuestro propio ser interior, y con el entorno del cual formamos parte. Desde luego, resulta extremadamente difícil modificar formas cristalizadas en nuestra historia, social y personal y poner en práctica otras, más aún si tomamos conciencia de la realidad cambiante, abierta, heterogénea, azarosa, controversial, reticular y con altos grados de indeterminación de la cual formamos parte, además de correr el riesgo de que las relaciones autodestructivas que hemos ido acumulado se magnifiquen y hagan realidad las predicciones del fin de nuestro mundo.

No obstante, se trata de desestructurar una enmarañada red de conexiones entre poderes establecidos, que podrían ser desplazados, o al menos debilitados, por nuevas formas de pensar y actuar. De su- perar temores individuales y sociales, cuya angustia se cree que se maneja mejor desde las certezas, de construir espacios conformados, por patrones cerrados, repetitivos, y desde el control externo. En suma, de derribar barreras objetivadas que constriñen el cambio, pero que admitiendo la incertidumbre, aceptando la responsabilidad de la auto-organizacióny la autocrítica de costumbres y tradiciones, actitudes reforzadas y reproducidas por la educación y la investigación, conducen hacia la meta de la autonomía.

Sin duda, pensar la realidad histórico concreta y no una realidad inventada, exige una actitud crítica ante los constructos hegemónicos, un distanciamiento de ellos (distanciamiento que es función del pensar epistémico) y evitar la trampa que puede significar el canon metodológico para el pensamiento, si quedamos prisioneros de un armazón metodológico que impide reconocer formas emergentes de la realidad (Zemelman, 2001:6).

\section{Alternativas desde la Pedagogía crítica}

La crisis de la institución escolar lleva a la búsqueda de alternativas y desde la Pedagogía crítica puede vislumbrarse una de alto potencial y viabilidad. La pedagogía entendida como el estudio de los procesos educativos que involucran a la persona que aprende y a la persona que enseña, tales como, los métodos, técnicas, procesos psicológicos, cognitivos, sociales, etc., permiten la adecuada apropiación del conocimiento. Pero el binomio Pedagogía-crítica, entiende que junto con los anteriores procesos se han de tener en cuenta conceptos 
como: emancipación, resistencia, concientización, problematización, participación y transformación. Son acciones reflexivas que integran teoría y práctica, por lo que debe concebirse como una síntesis entre conciencia reflexiva y acción ética y política (Freire, 1980).

La Pedagogía crítica surge como una necesidad ante las prácticas educativas predominantes de transmisión del conocimiento, en donde el alumno es mero receptor de conceptos, en un acto pasivo y sumiso, repitiendo patrones de comportamiento de acuerdo al contexto social que le rodea. Parsons (1990), describe muy bien la función de cada individuo en el aula, entendida como microsistema social, en donde dependiendo del contexto social, cultural, económico, político y religioso del que cada uno fue estimulado, ha de encontrar su lugar en una sociedad, dejando de lado la posibilidad de una transformación en el sujeto a partir de su deseo y derecho genuino de superación.

Es decir, la repetición de roles a partir del hecho de haber crecido en una familia con determinadas características y la impronta del oficio y/o actividad para la que ha sido estimulado, coarta la potencialidad individual de cada persona desde sus metas y perspectivas en la vida. Subestima al hombre común, por una fuerte inclinación al gregarismo que caracteriza la masificación (Freire, 1980).

La práctica de la educación en distintos escenarios, tales como el salón de clases, los diversos espacios de los que se sirven los movimientos sociales, o en la vida cotidiana, han de permitir la relación con situa- ciones concretas donde la crítica ejerza su carácter reflexivo-teórico e integrador a la acción desde la pedagogía.

De este modo, la emancipación, resistencia, liberación, concientización, problematización, participación y transformación no surgen como acciones separadas, pues todas son acciones articuladas en la dinámica de la Pedagogía crítica, a la vez que no hay emancipación sin acciones de resistencia, ni resistencia que no pretenda la liberación o la transformación. El individuo que desarrolla su criticidad es un sujeto participativo, ya que la necesidad de un cambio ha de traducirse en acciones concretas, que tengan como objetivo principal la liberación de un colectivo reprimido, sujeto a intereses ajenos a los propios, sin más motivación que aquella de satisfacer estándares inalcanzables por mínimos estímulos que beneficien al individuo y a su vez permitan la estabilidad de quienes le rodean.

Como se ha visto, la Pedagogía crítica surge como un medio alternativo y colectivo para que los oprimidos puedan autoliberarse, puedan resistir a la coacción y formas de enseñar que imponen y excluyen, $e$ inevitablemente puedan transformar su realidad. Esas prácticas pedagógicas requieren específicamente, en su afán incluyente, de una actitud participativa y dialógica, implicando formas de comunicación más allá del enunciado, la palabra misma o la razón instrumental. La comunicación de nuevas formas de significación, nuevos significados y de apropiarse de los ya existentes, lo cual denota su preocupación por el contexto, las prácticas culturales y educativas, los vínculos sociales y el sujeto mismo. 
La finalidad emancipadora que propone la Pedagogía crítica se basa en Adorno (1998), uno de los fundadores de la Escuela de Frankfurt, quien identifica a la educación como un acto de emancipación, en donde el individuo supera la barbarie y si ha de hacer uso de ella es en el sentido de la reflexión política.

Sin embargo, de ninguna manera se ha de mal entender que Adorno justifica actos de barbarie, aunque sí aclara que han de estar presentes en todo momento. $\mathrm{Y}$ es que, según Adorno, la autoliberación lleva al uso de una detonación hormonal innata en el hombre como integrante del reino animal, dado que una vez liberado su espíritu ha de tender a manifestarlo en actos de euforia, por el contrario si aún hay represión, la indignación y el enojo llevan a la manifestación de sus impulsos animales. Pero, "no es dignollegar al estado corderil, sino más bien hacer uso de la conciencia cabal, en donde el hombre manifieste su pensamiento y sea capaz de autorealizarse, de confrontarse a sí mismo con su realidad y a partir de ahí empezar a construir" (Adorno, 1998:112).

De ahí que la Pedagogía crítica busca "empoderar" a los sujetos para que sean constructores de sus propias vidas, que puedan desarrollar su autonomía, sean capaces de cuestionar, desafiar al sistema dominante, así como sus propias prácticas, valores y creencias establecidas, proponiendo sociedades solidarias, justas, incluyentes, participativas, democráticas.

Desde luego, este proceso no es fortuito ni espontáneo, requiere de agentes de cambio comprometidos y convencidos de autorregular sus procesos tanto formativos como formadores. Docentes convencidos de la anulación de prácticas y contenidos con fines de sometimiento, capaces de educar para el riesgo, para el esfuerzo por el cambio institucional, y para la lucha, tanto contra la opresión como a favor de la democracia fuera de las escuelas, en otras esferas públicas opositoras y en la sociedad en general (Giroux, 1997).

Con tal propósito, es imperativo adoptar la impronta intelectual que nos debe caracterizar, entendida como postura epistemológica, aquella que soporta la base del conocimiento conjuntando la experiencia y el pensamiento, sosteniendo juicios lógicamente necesarios y universalmente válidos no sólo sobre objetos ideales sino también sobre los objetos reales, derivados de la experiencia.

Giroux (1997) cree que es necesario que tanto profesores como estudiantes sean concebidos como intelectuales transformativos, si se quiere desarrollar una Pedagogía crítica que merezca el apelativo de política cultural. Siguiendo a Giroux, ser intelectual transformativo se concretiza en una forma de dedicación laboral en la que están íntimamente relacionados pensamiento y acción. Significa oponer una contra-ideología a las pedagogías instrumentales, que separan la concepción de la ejecución y desconocen la especificidad de las experiencias y formas subjetivas que perfilan la conducta, tanto del profesor como del estudiante.

Para la Pedagogía crítica, profesores y estudiantes apoyan, resisten o adaptan los lenguajes, las ideologías, los procesos sociales y los mitos que los sitúan dentro de las actuales relaciones de poder y depen- 
dencia. En este sentido, la Pedagogía crítica examina cómo se producen y transforman los procesos culturales dentro de los tres campos particulares del discurso: de producción; del análisis del texto; y el de las culturas vivas.

En el ámbito educativo, Giroux (1997) subraya que es importante hacer un énfasis en los materiales y en el proceso de instrucción, a partir de una mirada integradora y tratando de descubrir su punto focal y su objetivo. Por eso para él estudiar pedagogía no debería confundirse nunca con el hecho de que otros te digan lo que debes hacer.

Por esto, es necesario rescatar y reconocer las auténticas luchas que existen en este momento en México y otras partes del mundo, con el afán de definir proyectos educativos que sean verdaderamente transformativos y emancipadores.

Por lo que el docente ha de repensar sus experiencias para reconstruir su identidad misma, aquella que desde su interior produzca conocimiento crítico a partir de la práctica, conocer la realidad y aceptar la realidad para transformarla empezando desde el propio docente (Jara, 2012). Aquel docente que se dice y se practica en la intelectualidad sistematizada bajo el rigor científico de la investigación, ha de adoptar una actitud tendiente a la enseñanza integral, participativa, respetuosa e incluyente, tal como la describe Freire (1980):

- Enseñar exige que se respeten los saberes de los educandos

- Enseñar exige la corporización de las palabras por el ejemplo

- Enseñar exige respeto a la autonomía del ser del educando

- Enseñar exige seguridad, capacidad profesional y generosidad

- Enseñar exige saber escuchar

- Nadie es, si se prohíbe que otros sean.

Desde la visión de Adorno(1998), Foucault (1976), Illich (1979) y Freire (1980), entre otros impulsores de la Pedagogía crítica, el individuo ha de ser libre desde el momento en que se le dé la oportunidad de elección, se le permita confiar en sí mismo, se le impulse a conformar una identidad propia sin sumisión y sometimiento.

La escuela ha de ser un lugar de encuentro y socialización de ideas, donde se encuentre priorizada la generación de conocimiento sin fines jerárquicos, sino placenteros de gozo y disfrute, en donde no se someta a fechas y horarios estrictos, sino que el interés promueva jornadas de trabajo continuas en donde se comparta y divulgue abiertamente la posibilidad de concretar proyectos reales, necesarios para una sociedad sustentable, consciente e informada y capaz de tomar decisiones. Sin lamentos de lo que es, ni anhelos de lo que podría ser, sino construyendo, participando tomando decisiones que sean inclusivas y democráticas.

Se pretende la emancipación para construir (transformar), entre todos y todas, un modelo de vida alternativo, humanista, autónomo, inclusivo y utópico (inédito viable) que favorezca la vida y su futuro, es decir, lleva a la construcción de una propuesta ético-política.

Esa propuesta construida por los sujetos emancipados de aquellas realidades coti- 
dianas que los oprimen, obligan al docente tanto como al estudiante a tomar acción directa, activa, participativa y comprometida, el docente emancipador aprende de y con los estudiantes, favorece la interculturalidad, la construcción de una conciencia democrática, participativa, problematizadora y propositiva.

Los educadores críticos trabajan para revelar las condiciones materiales y sociales de la producción y recepción escolar, y no para servir a los postulados ideológicos e institucionales existentes en los centros de enseñanza o, para reducir los valores y habilidades de los grupos minoritarios y/o excluidos. La Pedagogía crítica reconoce como parte de su tarea denunciar la corriente pedagógica que esconde los currículos ocultos, el autoritarismo, la concentración de la riqueza, los abusos de poder, la destrucción de la naturaleza, la violencia y la corrupción.

La Pedagogía crítica se da a la tarea de transformar la sociedad, desde la transformación de la institución escolar al visibilizar los componentes que, a fuerza de su cotidianeidad, se vuelven invisibles y conforman el orden social. En síntesis, se trata de una propuesta teórica comprometida con profesores y alumnos para que asuman el rol de constructores del conocimiento y participen en el ejercicio del poder, binomio inseparable e indispensable para superar la crisis actual por la que atraviesa la institución escolar.

\section{Síntesis y Reflexiones finales}

La crítica a la escuela no es un rechazo a la misma, sino un clamor de dolor, angustia y desesperación de muchos de los actores directamente involucrados y afectados por la crisis en la que se encuentra. Por lo que el análisis aquí vertido no nos hace ajenos a la problemática, tanto a docentes como alumnos, sino todo lo contrario, permite centrar nuestros esfuerzos en las oportunidades que desde la Pedagogía crítica se pueden concretar para sortear los avatares que actualmente enfrenta la institución escolar. El hecho de cerrar los ojos a una dolorosa realidad no es el mejor camino, aunque muchos hemos sido parte activa, hay que encarar el problema.

Rotos los canales del diálogo, la educación tiende a ser reproductora y acrítica, se aleja de la transformación de los sujetos, dificultando la práctica de una Pedagogía crítica, emancipadora y transformadora. Aunque la reproducción sea la tendencia dominante, no elimina la condición antropológica de la resistencia y la liberación, por lo que, a pesar de las altas dosis de enajenación, los educandos y docentes resisten, luchan y hasta se emancipan a través de prácticas de aprendizaje alternativas que se desarrollan paralelamente al currículum oficial.

El docente ha de constituirse desde su rol de intelectual en actor de la transformación de sus propias prácticas, como reflejo de la autocrítica y autoobservación, permitiendo en sus alumnos la oportunidad de vivir modelos de enseñanza-aprendizaje críticos, analíticos, democráticos e incluyentes, que inviten a la reflexión crítica, retroalimentada por él mismo, para así estimular la autonomía en nuestros alumnos, conscientes, liberados, conformados desde la integridad 
de su condición humana, permitiendo el diálogo continuo con base en la correcta decodificación del mensaje y semántica adecuada.

Por lo tanto, desde la Pedagogía crítica es posible impulsar un proceso educativo, que involucre a docentes y alumnos, que emane de la crítica, el análisis y la inclusión, adoptando un estilo de vida que impacte en sus decisiones y entornos que les rodean. A fin de contribuir a formar individuos participativos, emancipados, capaces de articular desde una visión holística los elementos necesarios para afrontar situaciones cotidianas inaceptables en el contexto en el que les ha tocado vivir.

Más allá de las posiciones reduccionistas, es necesario ratificar - desde la Pedagogía crítica一, el carácter de educabilidad propio del ser humano, mismo que explica la capacidad de auto-transformación de los individuos, a través de prácticas de enseñanza-aprendizaje alternativas a las propias del currículum establecido por el sistema de educación gubernamental. Avanzando en la construcción de sí mismos, e influir en la transformación de las escuelas que son los microsistemas sociales en donde se desarrolla el proceso educativo.

En las escuelas hemos de avanzar en el diálogo inclusivo, construyendo nuevas ideas y aterrizando proyectos innovadores, donde la dinámica de participación permita superar la crisis de la institución escolar que hoy nos aqueja y avanzar hacia la transformación de la sociedad contemporánea, pero aún no es suficiente.

Desde la conformación de individuos críticos de su realidad, las escuelas han de ser espacios de reflexión y análisis en donde coexista la retroalimentación y la confrontación de saberes hacia la solución de las problemáticas enquistadas en nuestra sociedad, para lo cual la formación del docente ha de ser transformada para sustentar su práctica en procesos cognitivos sólidos, basados en la realidad del contexto en donde se desempeñan, conscientes de una realidad local-global y siendo parte activa de la institución escolar que tiene como fin la formación de individuos capaces de dialogar, tolerantes a las diversas formas de pensar y democráticos en la toma de decisiones.

Ciertamente, individuos conformados con tales características, han de enfrentarse a un sistema rapaz que busca a toda costa devorar su consciencia, buscando la alienación y cooptación de sí mismos al tratar de luchar contra un todo capitalista, sin embargo, apostamos a la ética de los sujetos que conocen la Pedagogía crítica, capaces de mantener firmemente su convicción en la igualdad social y luchando constantemente para que desde los diversos contextos en donde se encuentren, busquen impregnar a otros de esta forma de pensar, sin caer en la reproducción de conductas lesivas, actuando por convicción y claridad en pro de una educación incluyente y participativa.

En México los docentes han estado relacionados con la participación política activa, por lo que ha de reconocerse su colaboración en la conformación ideológica y política de nuestro país, aunque su preparación en este campo está descuidada, ya que los actores educativos con consciencia crítica se convierten frecuentemente en ac- 
tivos políticos para el sistema, por lo que su preparación es campo fértil que puede ser sembrado con elementos de la Pedagogía crítica. Para sacar de la crisis en la que se encuentra la institución escolar, hemos de ser educadores críticos con conciencia política y ética sin perder el sentido nato de quiénes somos y cuál es el objetivo central de nuestro quehacer educativo.

Si bien es cierto las escuelas formadoras de formadores se han caracterizado por su impronta educativa y compromiso social, se requieren individuos que se asuman como intelectuales, preparados política y socialmente, dispuestos a promover movimientos sociales, informados y organizados, en torno a demandas que signifiquen una verdadera transformación del status quo.

Sin duda, las instituciones educativas llevan sobre sus hombros la responsabilidad de la formación de individuos conscientes, críticos, analíticos y participativos, éticos y conscientes de su realidad social, que motiven cambios significativos en el contexto que les rodea y los determina, así como formar liderazgos auténticos sustentados en ideales viables, solo así la crisis de nuestra institución escolar habrá de ser superada y por ende la de todo un país.

\section{Referencias}

Adorno, T. (1998). Educación para la emancipación. Madrid:Morata.

CIRET-UNESCO. (1997). ¿Qué universidad para el mañana? Hacia una evolución transdisciplinaria de la universidad. Declaración y recomendaciones del Congreso Internacional sobreTransdisciplinariedad. Suiza: Locarno.

De VriesWietse, Vázquez-Cabrera, R. y Rios-Treto D. (2013). Millonarios o malparados: ¿de qué depende el éxito de los egresados universitarios?.Revista Iberoamericana de Educación Superior, 4(9).Recuperado de https://ries.universia.net/article/view/97

Foucault, M. (1976). Vigilar y Castigar: nacimiento de la prisión. México: Siglo XXI.

Freire, P. (1980). La Educación como Práctica de Libertad. México: Siglo XXI.

Freire, P. (2006). Pedagogía de la Indignación.México: Morata.

Giroux, H. (1997). Los profesores como intelectuales. Hacia una pedagogía crítica del aprendizaje. Barcelona: Paidos.

Granja Castro, J. (2007). "Narrations and Knowledges at the Beginnings of Modern Schooling in Mexico", PaedagogicaHistorica. International Journal of the History of Education, 6 (43), 819-837.

Granja Castro, J.(2011). El lenguaje escolar de la desigualdad en el umbral de la "primera oleada de expansión" de la enseñanza obligatoria: México en la segunda mitad del siglo XX. Revista mexicana de investigación educativa, 16(48), 17-42.

Illich, I. (1979). Un mundo sin escuelas. México: Nueva imagen.

Jara, H.Ó. (2012). "Sistematización de Experiencias, Investigación y Evaluación: Aproximaciones desde tres ángulos". Revista internacional sobre investigación en educación global y para el desarrollo.1,56-70.

Kant, I.(1973). Crítica de la razón pura. Buenos Aires: Losada.

McPherson, CrawfordBrough. (2005).La teoría política del individualismo posesivo. De Hobbes a Locke. España:Trotta.

OCDE, Education at a Glance 2012 (2012). OECD Indicators, ECD Publishing. En http://dx.doi. org/10.1787/eag-2012-en, p. 35.

SITEAL (2011). http://www.siteal.iipe-oei.org/ Instituto de Estadística de la UNESCO, Compendio mundial de la educación 2011. http://www.uis.unesco.org, pp. 262 y ss.

Parsons, T. (1990).El aula como sistema social. Sus funciones en la sociedad americana. En Educación y Sociedad. Revista trimestral de educación. (6), 173-195.

Zemelman, H. (2001). Pensar teórico y pensar epistémico. Los retos de las Ciencias Sociales latinoamericanas.Material escrito de la Conferencia Magistral dictada en la Universidad de la Ciudad de México. Recuperado el 1 de febrero de 2011 en: http://www. ipecal.edu.mx/Biblioteca/Documentos/Documento7.pdf 